\title{
Can selection explain the protective effects of farming on asthma?
}

\author{
Wijnand Eduard ${ }^{1,2}$, Vivi Schlünssen ${ }^{3}$, Torben Sigsgaard ${ }^{3}, \varnothing$ yvind Omland $^{3,4}$, Neil Pearce ${ }^{2,5}$, \\ Jeroen Douwes ${ }^{2}$ \\ ${ }^{1}$ Department of Chemical and Biological Work Environment, STAMI National Institute of Occupational Health, Oslo, Norway \\ ${ }^{2}$ Centre for Public Health Research, Massey University, Wellington, New Zealand \\ ${ }^{3}$ Department of Public Health, Section for Environment, Work and Health, Aarhus University, Aarhus, Denmark \\ ${ }^{4}$ Department of Occupational Medicine, Aalborg University Hospital, Aalborg, Denmark \\ ${ }^{5}$ Department of Medical Statistics, London School of Hygiene and Tropical Medicine, London, United Kingdom
}

Eduard W, Schlünssen V, Sigsgaard T, Omland $\varnothing$, Pearce N, Douwes J. Can selection explain the protective effects of farming on asthma? Ann Agric Environ Med. 2015; 22(3): 467-469. doi: 10.5604/12321966.1167715

\begin{abstract}
Introduction and objective. Reduced asthma and allergy risks in farmers have been ascribed to microbial exposures. However, selection may also play a role and this was assessed in two Scandinavian farming populations.

Materials and methods. Asthma prevalence in 739 Danish farming students was compared to that of 1,105 siblings. 8,482 Norwegian farmers were also compared with 349 early retired farmers.

Results. The prevalence of ever-asthma was 5.4\% in farming students and 5.2\% in siblings (OR 1.1; 95\% Cl 0.73-1.7). Current asthma in farmers was $3.0 \%$ compared to $6.3 \%$ in farmers who had retired early (OR 1.8, $95 \% \mathrm{Cl} 1.1-2.9)$. Adjustments for early retirement increased the asthma prevalence by $0.3-0.6 \%$. Farmers who had changed production were more likely to have asthma (OR 9.8, 95\% Cl 6.0-16).

Conclusions. No healthy worker selection into farming was observed and changes in asthma prevalence due to early retirement were small. Selection effects are therefore unlikely to explain the protective effects of farming on asthma.
\end{abstract}

Key words

Farmers, farming students, healthy worker selection, survivor selection, cross-sectional study

\section{INTRODUCTION}

Several studies have reported reduced risks of atopy, hay fever, atopic dermatitis and asthma in farmer's children [1, 2]. Protective effects of farming have also been shown in adolescents and adult farmers, although the evidence has been mixed, with some studies showing increased risks of asthma and atopy and others showing no association or a reduced risk [3].

It has been hypothesized that microbial exposure, and particularly diversity of microbial exposure, may partially account for the reduction in allergy and asthma risk in farmers and farmers' children [4]. Consumption of raw milk may also be important [5]. Selection effects involving asthmatics avoiding farm jobs with high exposure and/or leaving high-exposed farm jobs have not previously been studied as an alternative explanation, despite the 'healthy worker effect' being particularly strong in the case of asthma [6]. If these effects exist in farming, then they may not only explain the reduced risk in adult farmers, they may also (through generations of selection) in part explain the reduced risks in farmers' children.

\section{OBJECTIVE}

To assess selection effects with regards to asthma in Danish farming students and their siblings. Also assessed were the

Address for correspondence: Wijnand Eduard, Department of Chemical and Biological Work Environment, STAMI National Institute of Occupational Health, P.O. Box 8149Dep, NO-0033 Oslo, Norway

E-mail: wijnand.eduard@stami.no

Received: 07 April 2014; accepted: 20 January 2015 effects on asthma of early retirement and changes in type of farm production among Norwegian farmers.

\section{MATERIALS AND METHOD}

Danish study. All second-year students from farming schools in Denmark were invited (1992-1994) to participate in a cross-sectional study of allergies and asthma $(\mathrm{N}=1,964$; participation rate 79\%) [7]. Students were asked the following questions: (1) Do you have asthma? (2) Have you ever had asthma? (3) Do any of your siblings have or have had asthma? (4) How many of your siblings have or have had asthma? The number of siblings was obtained from a postal questionnaire completed by the parents. Most farming students were males (89\%), $42 \%$ had been raised on a farm, $25 \%$ were active smokers and mean age was 19.0 years $(\mathrm{SD}=1.83)$. Of the siblings, $47 \%$ were male; no information, on smoking, age and farm childhood was available. Farm childhood status was therefore assumed to be the same in siblings and students from the same family. Since no gender-specific information on asthma among siblings was available, only students with either sisters or brothers (i.e. 739 students: and 1,105 siblings) were selected.

Norwegian study. Current asthma was assessed in 8,482 farmers from south-east Norway examined in 1991 (participation rate $79 \%$ ) by a self-administered questionnaire with the questions: (1) Have you ever had asthma? (2) If yes, do you have asthma now? (3) Was asthma diagnosed by a physician? Ever asthma was defined as a positive response to any of these questions [8]. The population included 349 farmers who had retired from farming before the legal 
pension age four years prior to the study being conducted, and 104 farmers who had changed production because of dust-related health symptoms. The mean age was 49 years (SD 11), 66\% were male, and 30\% were current smokers, $24 \%$ former smokers and $46 \%$ never smokers.

Ethics approval. The Danish study was approved by the Danish Ethics Committee in 1991 and all participants gave written consent. The Norwegian study was approved by the Norwegian Data Inspectorate and the Regional Medical Ethics Committee in 1989. Informed consent was not required in Norway in 1989.

Data analysis. Comparisons in asthma prevalence between Danish farming students and siblings and current and retired farmers in Norway were made using logistic regression analyses adjusting for gender, age and smoking.

For the Norwegian farmers we included those who had retired early during the previous four years, but no data for earlier time periods was available. To adjust for this, estimated proportions of retired farmers in the source population (including those who had left prior to the previous four years) was used. This was carried out separately for male and female farmers. The proportion of farmers in the study population who had retired early during the last 4 years was estimated from logistic regression models of retirement with age. Annual retirement rates in age strata were estimated by the proportion of early retired farmers divided by 4 years. The proportion of early retired farmers in the source population was subsequently estimated as per the formula below:

$$
p_{\text {retired }_{i}}=\left(1-p_{\text {annual }_{i}}\right)^{\text {Year }_{\text {farming }_{i}}}
$$

where

Year $_{\text {farming }_{i}}={\text { arithmetic mean years in farming in age- } \text { group }_{\mathrm{i}}}$

Asthma prevalences in age-groups (categorised in quartiles) of active and early retired farmers were estimated in the study population using logistic regression. The asthma prevalence estimate was then adjusted using the proportions of early retired farmers from the estimated source population in each age group.

\section{RESULTS}

Danish study. No difference in asthma prevalence was found between students (5.4\%) and siblings (5.2\%; OR 1.1; 95\% CI 0.7-1.7) (Tab. 1). In a separate logistic regression of students only, age was not associated with asthma (OR 1.00; 95\% CI 0.9-1.1). Current smoking was positively associated with asthma, but this was only of borderline statistical significance (OR 1.5; 95\% CI 1.0-2.4).

Norwegian study. The prevalence of current asthma in farmers who retired early was $6.3 \%$, compared to $3.0 \%$ in active farmers (OR 1.8; 95\% CI 1.1-2.9), and 22\% in farmers who had changed production (OR 9.8; 95\% CI 6.0-16). Early retirement was also associated with an increased prevalence of ever asthma (9.2\% compared to $6.1 \%$ in active farmers (OR 1.6; 95\% CI 1.1-2.3). No significant association was found with physician-diagnosed asthma (5.7\% compared to $4.0 \%$. OR $1.4 ; 95 \%$ CI $0.9-2.3$ ).
Table 1. Prevalence of ever asthma in Danish farming students and their siblings by gender and childhood on a farm

\begin{tabular}{lcccccc}
\hline & \multicolumn{3}{c}{ Students } & \multicolumn{3}{c}{ Siblings } \\
\hline & \multicolumn{3}{c}{ Asthma } & & & Asthma \\
\hline Factor & $N_{\text {all }}$ & $N$ & $\%$ & $N_{\text {all }}$ & $N$ & $\%$ \\
\hline Gender & & & & & & \\
$\quad \begin{array}{l}\text { Female } \\
\quad \text { Male }\end{array}$ & 81 & 3 & 3.7 & 586 & 28 & 4.8 \\
\hline Farm childhood & 658 & 37 & 5.6 & 519 & 29 & 5.6 \\
$\quad$ Yes & 313 & 19 & 6.1 & 518 & 27 & 5.2 \\
$\quad$ No & 426 & 21 & 4.9 & 587 & 30 & 5.1 \\
\hline Total & 739 & 40 & 5.4 & 1,105 & 57 & 5.2 \\
\hline
\end{tabular}

Adjustments for early retirement using estimated proportions of retired farmers in the source population increased the estimates of current asthma from $3.1 \%$ to $3.7 \%$, ever asthma from $6.3 \%$ to $6.8 \%$ and physician-diagnosed asthma from $4.1 \%$ to $4.4 \%$. (Tab. 2).

Table 2. Asthma in Norwegian farmers by gender. Observed prevalences in active farmers, early retired and all farmers and adjusted prevalences using early retirement rates from the estimated source population

\begin{tabular}{llcccccccc}
\hline \multicolumn{7}{c}{$\begin{array}{c}\text { Active } \\
\text { farmers }\end{array}$} & $\begin{array}{c}\text { Early retired } \\
\text { farmers }\end{array}$ & All farmers & Adjusted \\
prevalence \\
\hline Outcome & Gender & $\mathrm{N}$ & $\%$ & $\mathrm{~N}$ & $\%$ & $\mathrm{~N}$ & $\%$ & $\%$ \\
\hline Current & Male & 5410 & 3.1 & 158 & 7.0 & 5568 & 3.2 & 3.7 \\
asthma & Female & 2723 & 2.7 & 191 & 5.8 & 2914 & 2.9 & 3.6 \\
& All & 8133 & 3.0 & 349 & 6.3 & 8482 & 3.1 & 3.6 \\
\hline Doctor- & Male & 5410 & 4.2 & 158 & 7.0 & 5568 & 4.3 & 4.6 \\
diagnosed & Female & 2723 & 3.7 & 191 & 4.7 & 2914 & 3.8 & 4.0 \\
asthma & All & 8133 & 4.0 & 349 & 5.7 & 8482 & 4.1 & 4.4 \\
\hline \multirow{2}{*}{ Ever } & Male & 5410 & 6.5 & 158 & 10.1 & 5568 & 6.6 & 7.1 \\
asthma & Female & 2723 & 5.4 & 191 & 8.4 & 2914 & 5.6 & 6.3 \\
& All & 8133 & 6.1 & 349 & 9.2 & 8482 & 6.3 & 6.8 \\
\hline
\end{tabular}

\section{DISCUSSION}

The prevalence of ever asthma in Danish farming students and their siblings was almost identical, i.e. $5.4 \%$ and $5.2 \%$, respectively. In Norwegian farmers, current asthma was significantly more prevalent in early retired farmers than in active farmers i.e. $6.3 \%$ and $3.0 \%$, respectively. However, due to the relatively small number of early retirees, current asthma in the total population of farmers was underestimated by only $0.6 \%$. The underestimation of doctor-diagnosed asthma and ever asthma was even lower, i.e. $0.3 \%$ and $0.5 \%$, respectively. The prevalence of current asthma was considerably higher in farmers who had changed production, i.e. $3 \%$ vs. $22 \%$, but this has no effect on asthma prevalence of the total farmers population.

The comparison of Danish students and siblings could not be adjusted for smoking and age as no information was available for siblings. However, age was not significantly associated with asthma in students, and is therefore unlikely to be a major confounder. Smoking may have been a confounder, but the effects would most likely have been small as 'only' $25 \%$ of the students smoked, and smoking habits between siblings are likely to be similar. Likewise, the genetic background and early life exposures of students and siblings are likely to be reasonably similar and these factors 
are therefore also unlikely to be significant confounders. The obtained data therefore suggest that a selection effect in this population of farmers' students is minimal. Other studies, on the other hand, have found that young adults with severe asthma less often chose a first job which involved exposure to dust and gases or allergens [9]. However, the effects were not strong and the evidence has been mixed [10].

The number of all farmers who had left the study population due to early retirement was estimated, based on early retirement data for the four year period prior to commencing the study. These calculations were based on the assumption that the early retirement rate was constant during all years in farming within all age groups. However, these trends may have been lower earlier in life especially in the older age groups. The adjusted prevalences are therefore probably overestimated.

When the presented data is compared with a study of the general population in south-west Norway conducted a few years before the current study, it was found that ever physician-diagnosed asthma in rural and urban populations was $5.7 \%$ and $7.6 \%$, respectively, which was significantly higher by $1.7 \%$ and $3.6 \%$ than in our farming population [11]. In fact, the difference was considerably greater than the underestimation of $0.3 \%$ found for physician-diagnosed asthma in the presented analysis. Thus, it seems unlikely that the small selection effects from early retirement of asthmatic farmers observed in this study can fully explain the lower asthma prevalence in Norwegian farmers.

Farmers who had changed the type of production had an increased risk of current asthma (OR 9.8), compared with those who had not changed production, indicating a strong selection effect. Such selection may distort the asthma prevalence among farmers with a specific type of production, but not in the whole farming population. However, only $1.3 \%$ of the Norwegian farmers had changed production during the last 10 years, therefore the resulting bias in comparisons between farmers with different production types is small.

\section{CONCLUSIONS}

There was no evidence for healthy worker selection into farming among Danish farming students born in 1974. A healthy survivor selection was observed in Norwegian farmers, but it was too small to fully explain the reduced risk of asthma observed in this population. A strong selection effect was observed among farmers who had changed production type, which may bias comparisons between different type of farmers, but not the asthma risk in the whole farming population. Thus, the postulated protective effects of farming on asthma appear unlikely to be attributable to selection effects alone.

\section{Acknowledgements}

The study was supported by Norwegian Research Council Grant No. 103544/110 and Danish Medical Research Council Grant No. 09-060086, sponsored by the Health Research Council (HRC) of New Zealand.

\section{REFERENCES}

1. von Mutius E. Asthma and allergies in rural areas of Europe. Proc Am Thorac Soc. 2007; 4(3): 212-216.

2. Flohr C, Yeo L. Atopic dermatitis and the hygiene hypothesis revisited. In: Shiohara T (ed). Pathogenesis and management of Atopic Dermatitis. Curr Probl Dermatol, Basel, Karger. 2011; 41: 1-34.

3. Omland $\varnothing$. Exposure and respiratory health in farming in temperate zones -a review of the literature. Ann Agric Environ Med. 2002; 9(2): 119-136.

4. Ege MJ, Mayer M, Normand AC, Genuneit J, Cookson WO, BraunFahrländer C, Heederik D, Piarroux R, von Mutius E; GABRIELA Transregio 22 Study Group. N Engl J Med. 2011; 364(8): 701-709.

5. Braun-Fahrländer C, von Mutius E. Can farm milk consumption prevent allergic diseases? Clin Exp Allergy. 2011; 41(1): 29-35.

6. le Moual N, Kauffmann F, Eisen EA, Kennedy SM. The healthy worker effect in asthma: work may cause asthma, but asthma may also influence work. Am J Respir Crit Care Med. 2008; 177(1): 4-10.

7. Omland $\varnothing$, Sigsgaard T, Hjort C, Pedersen OF, Miller MR. Lung status in young Danish rurals: the effect of farming exposure on asthma-like symptoms and lung function. Eur Resp J. 1999; 13(1): 31-37.

8. Eduard W, Douwes J, Omenaas E, Heederik D. Do farming exposures cause or prevent asthma? Results from a study of adult Norwegian farmers. Thorax 2004; 59(5): 381-386.

9. Dumas O, Smit LA, Pin I, Kromhout H, Siroux V, Nadif R, et al. Do young adults with childhood asthma avoid occupational exposures at first hire? Eur Respir J. 2011; 37(5): 1043-1049.

10. Radon K, Schulze A, Nowak D. Inverse association between farm animal contact and respiratory allergies in adulthood: protection, underreporting or selection? Allergy 2006; 61(4): 443-446.

11. Eduard W, Omenaas E, Bakke P, Douwes J, Heederik D. Atopic and non-atopic asthma in a farming and a general population. Am J Ind Med. 2004; 46(4): 396-399. 